JURNAL ILMU PENDIDIKAN DAN EKONOMI

Halaman Jurnal: https://journal.staidenpasar.ac.id/index.php/wb

Halaman Utama Jurnal : https://journal.staidenpasar.ac.id/index.php

\title{
STRATEGI DAN PERAN PENTING KOMITE NASIONAL EKONOMI DAN KEUANGAN SYARIAH (KNEKS) DALAM MENDUKUNG KETAHANAN EKONOMI NASIONAL
}

\author{
Kusjuniati \\ kusjuniati@staidenpasar.ac.id
}

\begin{abstract}
ABSTRAK
Komite Nasional Ekonomi dan Keuangan Syariah (KNEKS) merupakan lembaga yang berfungsi sebagai katalisator perkembangan ekonomi dan keuangan syariah dalam skala nasional maupun internasional. KNEKS diamanatkan untuk turut mendorong pengembangan ekonomi dan keuangan syariah guna mendukung ketahanan ekonomi nasional. Tugas KNEKS yaitu mempercepat, memperluas dan memajukan pengembangan ekonomi dan keuangan syariah dalam rangka memperkuat ketahanan ekonomi nasional. KNEKS memiliki Strategi yaitu Penguatan ekonomi dan keuangan syariah, Penguatan Halal Value Chain, Penguatan Usaha Mikro Kecil dan Menengah (UMKM), Penguatan Fatwa, Regulasi dan Tata Kelola.memperkuat penyediaan iklim usaha Industri Keuangan Syariah dan Industri Halal dengan adanya kepastian hukum, proses yang mudah dan tata kelola yang baik, Penguatan ekonomi digital. Memperkuat pelaku indistri halal dengan memanfaatkan dan mengoptimalkan layanan digital baik pembiayaan, pemasaran dan kapasitas produksi melalui penyediaan halal market place, pembentukan incubator start-up dan sistem informasi terintegrasi untuk traceability produk halal, Penguatan Literasi SDM, Riset dan Pengembangan. Memperkuat kesadaran publik mengenai konsep ekonomi syariah menuju penyediaan SDM yang berkualitas dan berkompetensi tinggi untuk mampu bersaing dan berinovasi melalui riset dan pengembangan.
\end{abstract}

\begin{abstract}
The National Committee for Sharia Economics and Finance (KNEKS) is an institution that functions as a catalyst for economic and sharia financial development on a national and international scale. The KNEKS is mandated to help encourage the development of the economy and Islamic finance to support national economic resilience. The task of the KNEKS is to accelerate, expand and advance the development of Islamic economics and finance in order to strengthen national economic resilience. KNEKS has Strategies namely Strengthening Islamic economic and finance, Strengthening Halal Value Chain, Strengthening Micro and Small and Medium Enterprises (UMKM), Strengthening Fatwa, Regulations and Governance. Strengthening the provision of the business climate of the Sharia Finance Industry, Industry and Halal Industry with legal certainty, easy and good governance, Strengthening the digital economy. Strengthening halal industry players by utilizing and optimizing digital services in financing, marketing and production capacity through the provision of halal market places, the establishment of start-up incubators and integrated
\end{abstract}


information systems for halal product traceability, Strengthening HR Literacy, Research and Development. Strengthening public awareness about the concept of Islamic economics towards the provision of high quality and highly competent human resources to be able to compete and innovate through research and development.

\section{PENDAHULUAN}

Komite Nasional Ekonomi dan Keuangan Syariah (KNEKS) merupakan lembaga yang berfungsi sebagai katalisator perkembangan ekonomi dan keuangan syariah dalam skala nasional maupun internasional. KNEKS diamanatkan untuk turut mendorong pengembangan ekonomi dan keuangan syariah guna mendukung ketahanan ekonomi nasional. ${ }^{1}$ Oleh karena itu pemerintah dibawah kepemimpinan presiden Joko Widodo mendirikan sebuah lembaga yang bernama Komite Nasinal dan Keuangan Syariah (KNKS) yang diresmikan pada tanggal 2 Agustus 2016 dalam rangka meningkatkan pembangunan nasional terutama pengembangan keuangan syariah. Seiring dengan pertumbuhan keuangan syariah kemudian pemerintah melalui Peraturan Presiden No.91 yang memberikan mandat bahwa KNKS diperluas menjadi KNEKS dengan Peraturan Presiden No. 28 tahun 2020. KNEKS memiliki tugas mempercepat, memperluas dan memajukan pengembangan ekonomi dan keuangan syariah dalam rangka mendukung pembangunan ekonomi nasional. KNEKS secara langsung dibawah kepemimpnan presiden Jokowi selaku Ketua dan Ketua Harian adalah wakil presiden yaitu M.Ma'ruf Amin sedangkan anggota dari KNEKS adalah : Kementrian Keuangan, Bank Indonesia, Otoritas Jasa Keuangan, Kementrian PPN/Bappenas, Kementrian Agama, Lembaga Penjamin Simpanan, Kementrian Koperasi dan UMKM dan Majelis Ulama Indonesia. Sedangkan Manajemen Eksekutif terdiri dari Direktur Eksekutif di jabat oleh Ventje Rahardjo merangkap sebagai Plt Direktur bidang Inovasi Produk, Pendalaman Pasar, Pengembangan Infra Struktur Pasar Keuangan, Direktur Bidang Keuangan Inklusif Dana Sosial Keagamaan dan Keuangan Mikro Syariah dijabat oleh Ahmad Juwaini, Direktur Bidang Pendidikan Dan Riset Keuanga Syariah dijabat oleh Sutan Emir Hidayat dan Direktur Bidang Pengembangan Ekonomi Syariah dan Industri Halal dijabat oleh Afdhal Aliasyar. Perubahan mendasar ada pada perubahan nama dan susunan struktural kelembagaan. KNEKS memiliki tugas dan fungsi lebih luas, tidak hanya di sektor 
keuangan syariah tapi juga ekonomi syariah secara menyeluruh. Wakil Presiden RI ditugaskan menjadi ketua harian. Ruang lingkup kerja KNEKS dalam ekonomi dan keuangan syariah meliputi empat hal. Yakni, pengembangan industri produk halal, pengembangan industri keuangan syariah, pengembangan dana sosial syariah, dan pengembangan dan perluasan kegiatan usaha syariah. Diharapkan dari terbentuknya struktur organisasi yang baru ini bisa mewujudkan amanah yang telah diberikan kepada manajemen KNEKS, agar pengembangan ekonomi dan keuangan syariah bisa maju sejajar dengan Negara-negara muslim lainnya bahkan diharapkan Indonesia bisa menjadi pemimpin dalam pengembangan ekonomi dan keuangan syariah di dunia.

\section{PEMBAHASAN}

Setelah adanya perubahan dalam nama menjadi Komite Nasional Ekonomi dan Keuangan Syariah kinerja lembaga tersebut terus dipacu dengan berbagai kegiatan, utamanya adalah pengembangan industri ekonomi dan keuangan syariah. Manajemen Eksekutif KNEKS tanpa henti melakukan berbagai sosialisasi dan edukasi tentang tugas dan fungsi KNEKS kepada masyarakat termasuk ke berbagai perguruan tinggi yang ada di Indonesia terutama perguruan tinggi yang memiliki program studi dan jurusan Ekonomi Syariah. Salah satunya adalah melakukan sosialisasi dan edukasi ke Sekolah Tinggi Agama Islam Denpasar, karena memilki program studi Ekonomi Syariah. Dengan adanya sosialisasi dan edukasi ini mahasiswa dan dosen serta civitas akademika STAI Denpasar dapat mengenal dan memahami tentang KNEKS secara mendalam dengan berbagai kegiatan yang dilaksanakan dalam rangka pengembangan ekonomi dan keuangan syariah di Indonesia. Berbagai perguruan tinggi di Indonesia yang memiliki program studi atau jurusan ekonomi syariah menjadi pusat perhatian dari KNEKS, dimana pada awalnya ketika masih bernama KNKS telah menjalin kerjasama dengan lima perguruan tinggi yaitu Intitut Pertanian Bogor, Universitas Airlangga, STEI Tazkia, Universitas Indonesia dan UIN Ar-Raniry. Kerjasama ini ditandai dengan melakukan nota kesepahaman atau Memorandum of Understanding (MoU). Nota kesepahaman ini ditanda tangani untuk pengembangan pendidikan, riset dan pengabdian pada masyarakat dibidang ekonomi syariah. Sedangkan penanda tanganan nota kesepahaman dengan Lembaga Ilmu Pengetahuan Indonesia (LIPI) dalam bidang penelitian dan pengembangan ekonomi syariah secara nasional. 
Penanda tanganan nota kesepahaman ini disaksikan langsung oleh presiden Joko Widodo pada tanggal 14 Mei 2019. Setelah KNKS berubah nama menjadi KNEKS berbagai perguruan tinggi di Indonesia juga telah melakukan nota kesepahaman untuk pengembangan pendidikan, riset dan pengabdian pada masyarakat dalam pengembangan ekonomi syariah.

Dengan perubahan nama dari KNKS menjadi KNEKS, lembaga ini tidak hanya terfokus pada keuangan syariah saja tetapi lebih menyeluruh terhadap ekosistem ekonomi syariah. Ruang lingkup KNEKS seperti yang diamanatkan PERPRES No. 28 tahun 2020 adalah : 1). Pengembangan industri produk halal, 2). Pengembangan industri keuangan syariah, 3). Pengembangan dana sosial syariah dan 4). Pengembangan dan perluasan usaha syariah. Berdasarkan PERPRES KNEKS tersebut pemerintah ingin mendorong pengembangan Lembaga Keuangan Mikro Syariah (LKMS), Bank Wakaf Syariah (BWS), BMT dan koperasi syariah sebagai bagian dari keuangan mikro. Produk keuangan lainnya yang akan dikembangkan oleh KNEKS adalah Kredit Usaha Rakyat (KUR) syariah dan Kredit Kepemilikan Rumah (KPR) syariah. Selama ini BWS atau bank wakaf syariah keuangannya hanya bersal dari donasi, ke depannya dapat didukung oleh APBN dan dana CSR dari BUMN. Ketua Harian KNEKS Ma'ruf Amin ingin mendorong wakaf menjadi dana abadi umat yang murah. Caranya adalah dengan membuat sukuk wakaf. Sukuk wakaf memiliki manfaat ganda selain untuk APBN juga memperbesar dana umat yang imbal hasilnya juga bisa dimiliki umat . untuk memperbesar dana wakaf ini KNEKS akan melibatkan BUMN. Dana wakaf ini dimaksudkan untuk membiayai lembaga-lembaga wakaf seperti rumah sakit untuk kaum dhuafa agar kaum dhuafa mendapatkan layanan kesehatan sebagaimana mestinya. Selain itu KNEKS juga akan membantu permodalan madani bagi UMKM yang membutuhkan modal yang bekerja sama dengan kementrian koperasi serta pengadaan serifikasi produk halal bagi UMKM tanpa dipungut biaya.

KNEKS memiliki strategi dalam melaksanakan tugasnya terutama yang dilakukan oleh manajemen eksekutif KNEKS yang mengharapkan bahwa pertumbuhan dan pengembangan ekonomi dan keuangan syariah Indonesia bisa lebih maju dari Negara-negara lain yang saat ini juga sedang mengembangkan perekonomian secara syariah seperti Inggris dan Negara Eropah lainnya. Strategi penguatan ekonomi dan keuangan syariah yang dimiliki oleh KNEKS untuk 
mengembangkan ekonomi dan keuangan syariah adalah :

1. Penguatan ekonomi dan keuangan syariah. Memperkuat ekonomi dan keuangan syariah melalui inovasi produk, pendalaman pasar dan pengembangan infrastruktur sistem keuangan sehingga menjadi pendorong pertumbuhan industri halal. Strategi ini sebenarnya telah dimiliki oleh lembaga keuangan syariah namun demikian penguatan ini harus tetap dikembangkan agar industri keuangan syariah memiliki ketahanan terutama perbankan syariah dimasa sulit seperti saat ini dalam masa covid 19 dan di masa resesi karena pengaruh pandemic covid 19. Lembaga keuangan syariah memiliki tujuan utama yaitu mensejahterahkan umat. Salah satu strategi yang perlu diperhatikan guna mencapai tujuan tersebut adalah mengintegrasikan keuangan komersial dan sosial syariah. Salah satu tujuan penting dari maqashid syariah adalah maslahah, yaitu memperbaiki keadaan umat dengan kesejahteraan yang merata. Peran keuangan sosial syariah yang berbentuk zakat akan membantu mustahik (yang berada dibawah garis kemiskinan) akan naik menjadi diatas garis kemiskinan. Dan yang sudah berada diatas akan mendapat bantuan agar menjadi bankable. ${ }^{2}$ Contoh produk dari lembaga keuangan syariah yang telah menerapkan integrasi ini adalah Cash Wakaf Linked Sukuk (CWLS), Link Aja Syarih (digital payment),Auto Debet Zakat, Infak, Sedekah dan Wakaf ( ZizWaf) dan asuransi jiwa syariah. Sedangkan dari sisi lembaga keuangan perbankan syariah memiliki keunggulan dibandingkan dengan perbankan konvensional yaitu dari sisi asset yang terprediksi karena menggunakan sistem bagi hasil dan bukan sistem tingkat suku bunga. Selain itu perbankan syariah memiliki penyanggah lain yaitu kepatuhan terhadap produk dan objek-objek dari pembiayaan yang diawasi oleh Dewan Pengawas Sayiah- Dewan Syariah Nasional- Majelis Ulama Indonesia (DSN_MUI), sehingga risiko pembiayaan yang keluar dari prinsip-prinsip syariah relative terjaga. Di masa pandemic covid 19 ini perbankan syariah masih relative aman dimana nasabah dari perbankan syariah tetap melakukan transaksi walaupun secara online dengan menggunakan internet banking dan mobile banking. Pandemic covid 19 ini tidak menyurutkan langkah dari perbankan syariah untuk tetap melakukan sosialisasi dan 
edukasi kepada masyarakat meskipun hanya melalui media elektronik dan media sosial seperti whattaps, facebook, twiterr dan instagram. Dengan cara seperti ini perbankan syariah telah melakukan digital marketing untuk memperluas market share dari perbankan syariah. Peran KNEKS terhadap perbankan syariah terlihat ketika memberikan solusi bagaimana perbankan syariah menghadapi kondisi pandemi covid 19.

2. Penguatan Halal Value Chain. Memperkuat seluruh rantai nilai industri halal dari hulu ke hilir melalui pembangunan halal hub di daerah, pengembangan standar halal, kampanye gaya hidup halal, penyediaan insentif bagi pelaku usaha dan pembangunan pusat halal internasional. Untuk menjadikan Indonesia sebagai Negara global hub syariah pemerintah akan membangun Kawasan Industri Halal (KIH). Kawasan ini bisa di dalam atau di luar Kawasan Ekonomi Khusus (KEK). Sejauh ini, sudah ada lima kawasan yang mengajukan diri untuk menjadi kawasan industri halal $(\mathrm{KIH})$. Kelima kawasan tersebut adalah Modern Cikande Industrial Estate, Bintan Inti Industrial Estate, Batamindo Industrial Park, Jakarta Industrial Estate Pulogadung, Kawasan Indutri Safe N Lock Sidoarjo, kawasan ini merupakan zona halal UMKM. Ketua Harian KNEKS Ma'ruf Amin menyampaikan bahwa KIH secara prinsip sudah jalan. Pengembangan KIH sudah masuk PERPRES dan Rencana Pembangunan Jangka Menengah Nasional (RPJMN). Oleh karena itu pengembangan $\mathrm{KIH}$ ini harus segera ditindaklanjuti di kementrian terkait dan segera harus dilaksanakan. ${ }^{3}$

Secara paralel Indonesia juga mengembangkan kemitraan dilevel international dengan mengadakan berbagai acara untuk memasarkan produk halal Indonesia. Berbagai acara telah dirancang untuk memasarkan produk-produk halal Indonesia yaitu melalui ISEF (Indonesia Sharia Economic Festival) yang ketujuh direncanakan tanggal 27-31 Oktober 2020 dan Halal Indutry Summit (HIS) yang rencananya akan diselenggarakan pada tanggal 1-3 Nopember 2020 tetapi karena masih pandemic covid 19 maka penyelengaraan ditunda sampai tahun 2021. Rencananya dalam HIS akan hadir 70 negara dan akan diadakan 
pembicaraan tentang industri halal secara global. Indonesia sendiri akan memasarkan produk-produk halal dan menjalin kerjasama dengan Negaranegara yang belum bersinergi dengan Indonesia. Diharapkan Indonesia dimasa yang akan datang tidak hanya mengekspor bahan mentah saja, tetapi juga barang jadi yang berkualitas dan memiliki standar halal.

3. Penguatan Usaha Mikro Kecil dan Menengah (UMKM). Memperkuat pelaku UMKM industri halal dan mendorong pencapaian pemerataan kesejahteraan dan kemandirian ekonomi bangsa melalui penyediaan program edukasi dan literasi, penyediaan fasilitas pembiayaan syariah terintegrasi serta pembangunan databasae UMKM. Komite Nasional Ekonomi dan Keuangan Syariah (KNEKS) mendorong peningkatan kualitas UMKM sektor industri halal termasuk melalui pesantren. Direktur bidang inklusif, Dana Sosial Keagamaan dan keuangan mikro syariah KNEKS Ahmad Juwaini menyampaikan dorongan untuk pengembangan pesantren dapat membantu pemulihan ekonomi masyarakat yang terpuruk akibat pandemi. ${ }^{4}$ KNEKS punya model ekosistem yang pada dasarnya untuk menyatukan semua pihak mulai dari fokus membantu mustahik atau mauquf alaih dan ada lembaga keuangan syariah yang membantu mereka. Peran KNEKS dalam ekosistem pengembangan ekonomi dan keuangan syariah berbasis pondok pesantren diterjemahkan melalui Pendirian Unit Layanan Keuangan Syariah (ULKS) Pesantren. ULKS berkolaborasi dengan berbagai lembaga keuangan syariah seperti BMT, bank syariah, non bank syariah, fintech syariah, layanan ZIS dan wakaf. ULKS dapat melayani simpanan dan transaksi, layanan pembiayaan juga layanan ZIS dan Wakaf di setiap pesantren. Kemudian mereka diarahkan untuk mengembangkan industri halal. Dalam perannya yang lain KNEKS berupaya melakukan bimbingan tehnis untuk pengelolaan bisnis sesuai standar industri dan pemanfaatan teknologi digital agar UMKM mampu memanfaatkan kemudahan teknologi mulai dari marketplace online, website dan fintek. Diharapkan dengan bimbingan ini keluar standar kurikulum bimbingan teknis pengembangan UMKM sektor industri halal 
yang seragam. Mencakup pengelolaan bisnis, keuangan, digitalisasi dan UMKM go-ekspor.

4. Penguatan Fatwa, Regulasi dan Tata Kelola.memperkuat penyediaan iklim usaha Industri Keuangan Syariah dan Industri Halal dengan adanya kepastian hukum, proses yang mudah dan tata kelola yang baik. Presiden Joko Widodo secara resmi meluncurkan Materplan Ekonomi Syariah Indonesia (MEKSI) 2019-2024. Diharapkan dengan peluncuran MEKSI 2019-2024 dapat menjadi acuan dalam rangka pengembangan ekonomi dan keuangan syariah. MEKSI 2019-2024 dipergunakan oleh KNEKS sebagai arah pengembangan ekonomi dan keuangan syariah, dimana MEKSI 20192024 memiliki strategi : Pertama,penguatan halal value chain dengan fokus pada sektor yang potensial dan memiliki daya saing tinggi. Kedua penguatan sektor keuangan syariah dengan rencana induk yang telah dituangkan dalam Masterplan Arsiktektur Keuangan Syariah Indonesia ( MAKSI) dan disempurnakan dalam rencana induk. Ketiga, penguatan sektor usaha kecil, mikro dan menengah (UMKM) sebagai penggerak utama halal value chain. Keempat,penguatan dibidang ekonomi digital utamanya perdagangan (e-commerce, market place) dan keuangan digital (fintek). Disamping itu pemerintah melalui KNEKS juga sedang menyiapkan Rancangan Undang-Undang, regulasi dan tata kelola yang berkaitan dengan ekonomi dan keuangan syariah. MUI sendiri juga telah menyiapkan undang-undang Jaminan Produk Halal (UU JPH) beserta pemerintah sebagai implementasinya. Seperti ketentuan tentang akreditasi dalam pembentukan Lembaga Pemeriksa Halal (LPH), penilaian aspek syar'i dalam kompetensi auditor halal dan penetapan fatwa halal untuk produk-produk konsumsi, makanan, minuman, obat-obatan dan kosmetika.

5. Penguatan ekonomi digital. Memperkuat pelaku indistri halal dengan memanfaatkan dan mengoptimalkan layanan digital baik pembiayaan, pemasaran dan kapasitas produksi melalui penyediaan halal market place, pembentukan incubator start-up dan sistem informasi terintegrasi untuk traceability produk halal. Memasuki era industry 4.0 dimana semua kegiatan ekonomi mulai bergeser menjadi serba digital, tak terkecuali Baitul Maal wat Tamwil (BMT). BMT sebagai salah satu lembaga 
keuangan syariah mikro yang merupakan lembaga keuangan syariah penggerak usaha rakyat harus bisa beradaptasi dengan era digitalisasi. Agar BMT bisa melayani masyarakat dengan kemudahan-kemudahan seperti menabung, melakukan pembiayaan dan payment lainnya. Digitalisasi BMT ini memiliki empat pilar yaitu pertama digitalisasi operasional, agar BMT memiliki teknologi informasi untuk membantu proses operasional secara efektif dan efesien, kedua, digitatalisasi pengawasan dan kepatuhan yang merupakan teknologi informasi agar pengelolaan BMT sesuai dengan prinsip-prinsip lembaga keuangan syariah, ketiga,digitalisasi pelayanan adalah penerapan teknologi informasi yang berkaitan dengan pelayanan yang dilakukan BMT untuk member kepuasan kepada masyarakat atau anggota, keempat,digitalisasi usaha adalah penerapan teknologi informasi yang berkaitan dengan kualitas dan kuantitas usaha dan merupakan teknologi informasi profit centre. Lebih dari dua ribu BMT yang telah menggunakan aplikasi digital core micro banking dari Pinbuk (pusat inkubasi usaha kecil) yang dinamakan Integrated Micro Banking System (IMBX) untuk membantu operasional BMT. Beberapa BMT juga telah menggunakan mobil MBT dan bahkan ada beberapa BMT yang juga telah menerapkan marketplace dalam opersionalnya. KNEKS memiliki peran yang sangat penting dalam pengembangan BMT agar BMT dapat bersinergi dengan keuangan syariah lainnya seperti fintek syariah, asuransi syariah, e-commerce halal agar dapat memperluas jangkauan layanannya dan mendorong inklusi keuangan syariah. Selain itu KNEKS juga mendorong hadirnya halal marketplace untuk memudahkan masyarakat berbelanja secara online. Pertumbuhan e-commerce di Indonesia memerlukan sistem penanda halal pada produk-produk yang dijual pada marketplace yang sudah ada dan maupun marketplace baru yang mengkhususkan pada produk halal. Untuk mewujudkan hal tersebut KNEKS telah melakukan kegiatan yang berupa Focus group Discussion (FGD) dan In-depth Interview pada tangl 14 maret 2019 dengan para pelaku e-commerce seperti Bukalapak, Tokopedia dan Shopee, Lembaga Negara, Bank Indonesia, Badan Pelaksana Jaminan Produk Halal (BPJH), DSN-MUI,LPPOM MUI, YLKI, dan Gabungan Pengusaha Makanan dan Minuman Seluruh Indonesia. Dalam acara tersebut KNEKS mengusulkan 
memberikan kemudahan untuk sertifikasi halal bagi pelaku UMKM. Pada tahap selanjutnya KNEKS akan melakukan penandatanganan kesepakatan untuk memperkuat kerjasama dalam tahap pengembangan halal marketplace bersama Bukalapak. Diharapkan Bukalapak akan menjadi pelopor di Industri e-commerce dalam membumikan halal marketplace.

6. Penguatan Literasi SDM, Riset dan Pengembangan. Memperkuat kesadaran publik mengenai konsep ekonomi syariah menuju penyediaan SDM yang berkualitas dan berkompetensi tinggi untuk mampu bersaing dan berinovasi melalui riset dan pengembangan. KNEKS melalui Master Plan Ekonomi Syariah Indonesia memiliki strategi pembangunan sumber daya manusia (SDM) untuk mewujudkan ekosistem ekonomi syariah di Indonesia. Terutama dalam membangun ekosistem industri halal di Indonesia, dibutuhkan sumber daya manusia yang kompeten dan berkualitas. "Pembangunan SDM unggul sejalan dengan visi pemerintah dalam RPJMN 2019-2024. Pendekatannya terlebih dahulu adalah hati(heart) yaitu satukan tujuan untuk bertakwa kepada Allah,Tuhan YME. Kemudian penuhi dengan pengetahuan (head), serta penuhi dengan kemampuan (skill) spesifik pada industri tertentu (hands). Hal itu bisa ditempuh dengan sertifikasi profesi serta kemampuan spesifik tertentu"5. Pengembangan SDM unggul dapat melalui edukasi SDM melalui berbagai bidang pendidikan baik tingkat menengah maupun perguruan tinggi dengan menyisipkan materi keuangan dan ekonomi syariah atau industr halal dalam kurikulum pendidikan, standardisasi profesi, penyediaan SKKNI, sosialisasi ekonomi syariah sebagai lifestyle dan program-program edukasi lainnya seperti pameran dan event-event tertentu. KNEKS menjalin kerjasama dengan berbagai perguruan tinggi baik negeri maupun swasta dalam rangka riset dan pengembangan utamanya riset dan pengembangan keuangan dan ekonomi syariah menuju industri halal. Peran KNEKS tidak hanya berhenti disini saja tetapi tugas dan fungsinya masih sangat dibutuhkan oleh masyarakat luas terutama para pelaku usaha baik dibidang keuangan dan ekonomi syariah maupun UMKM yang bergerak dalamindustri halal dan masyarakat muslim yang membutuhkan produk-produk halal seperti makanan, minuman, obatobatan dan kosmetika. Serta berbagai edukasi dan sosialisasi ke masyarakat 
melalui perguruan tinggi dan sekolah-sekolah menengah yang memiliki jurusan keuangan dan ekonomi syariah dan pondok pesantren di seluruh Indonesia. Sesuai dengan tugas KNEKS yaitu mempercepat, memperluas dan memajukan pengembangan ekonomi dan keuangan syariah dalam rangka memperkuat ketahanan ekonomi nasional, meskipun dalam masa pandemic covid 19 tidak menyurutkan langkah KNEKS untuk tetap melaksanakan tugasnya agar ketahanan ekonomi nasional tetap kuat. Dalam masa pandemi covid 19 tugas-tugas dan kegiatan tetap dilaksanakan oleh manajemen ekskutif KNEKS untuk tetap memberikan sumbangsih kepada Negara, masyarakat dan bangsa. Berbagai edukasi dan sosialisasi dilaksanakan terutama tentang keuangan dan ekonomi syariah dengan menyelenggarakan seminar secara online atau webinar melalui media zoom dan youtube serta peluncuran buku yang ditulis oleh para pakar dari dalam negeri maupun luar negeri. Webinar yang dilaksanakan baik secara nasional maupun internasional melibatkan pakar keuangan dan ekonomi syariah yang tergabung dalam Negara-negara islam dan peluncuran buku oleh KNEKS diharapkan dapat dipergunakan sebagai acuan oleh para pelaku usaha keuangan syariah,investasi modal syariah, industri halal dan UMKM khusus produk halal dalam menghasilkan produk dan jasa. Terutama dalam menghadapi masa pandemi covid 19 ini. Dalam buku tersebut KNEKS memberikan rekomendasi dan solusi untuk menghadapi peluang dan mengatasi tantangan bagi keuangan syariah. Rekomendasi tersebut tertuang dalam buku yang berjudul : Impact of The Covid 19 Outbreak On Islamic Finance In The OIC Countries. Semoga apa yang telah diupayakan oleh KNEKS bisa segera terwujud untuk kemaslahatan masyarakat dan bangsa demi pengembangan dan penguatan serta ketahanan ekonomi dan keuangan syariah secara nasional. 


\section{Daftar Pustaka :}

Kumpulan Kultum Ekonomi Syariah 2, KNEKS, Jakarta, 2020 Harian Kompas, Jakarta, Senin 18 Mei 2020

Harian Republika.co.id, Jakarta, Kamis, Juni 2020 Website resmi KNEKS, Jakarta, 2020

Webinar, Integrasi Keuangan komersial dan Sosial Syariah, Jakarta, 22 Mei 2020.

Berbagai sumber berita-berita KNEKS. 